\title{
VIRGIN ISLANDS OF THE UNITED STATES
}

Area: 132 sq. km

Population: 95,591

Capital: Charlotte Amalie

The Virgin Islands Police is controlled by the local Department of Public Safety. Applicants must be US citizens and residents of the islands. Crime levels are negligible, even during the tourist season, and thus its current 400-man strength is considered sufficient.

Virgin Islands Police, PO Box 210, Charlotte Amalie 